\title{
Cometary dust in Antarctic micrometeorites
}

\author{
Naoya Imae \\ Antarctic Meteorite Research Center, National Institute of Polar Research, \\ 10-3, Midori-cho, Tachikawa, Tokyo 190-8518, Japan \\ email: imae@nipr.ac.jp
}

\begin{abstract}
Cometary nuclei consist of aggregates of interstellar dust particles less than $\sim 1 \mu \mathrm{m}$ in diameter and can produce rocky dust particles as a result of the sublimation of ice as comets enter the inner solar system. Samples of fine-grained particles known as chondritic porous interplanetary dust particles (CP-IDPs), possibly from comets, have been collected from the Earth's stratosphere. Owing to their fine-grained texture, these particles were previously thought to be condensates formed directly from interstellar gas. However, coarse-grained chondrule-like objects have recently been observed in samples from comet $81 \mathrm{P} /$ Wild 2 . The chondrule-like objects are chemically distinct from chondrules in meteoritic chondrites, possessing higher $\mathrm{MnO}$ contents $(0.5 \mathrm{wt} \%)$ in olivine and low-Ca pyroxene. In this study, we analyzed AMM samples by secondary electron microscopy and backscattered electron images for textural observations and compositional analysis. We identified thirteen AMMs with characteristics similar to those of the $81 \mathrm{P} /$ Wild 2 samples, and believe that recognition of these similarities necessitates reassessment of the existing models of chondrule formation.
\end{abstract}

Keywords. chondrule, chondrule-like object, micrometeorite, comet, forsterite, enstatite

\section{Introduction: A Review of Cometary Dust}

The internal structure of cometary nuclei has long been considered, theoretically at least, to be the result of aggregation of interstellar dust particles with diameter $<1 \mu \mathrm{m}$ (Greenberg \& Hage 1990). Previous studies have modeled the internal structure of these particles, which are now known to have a silicate core mantled with organics and covered by ice. Their weight ratio of silicate, organics, and ice according to the solar elemental abundance is nearly $1: 1: 1$ (Greenberg 1998). The interstellar dust particles are thought to have formed by condensation from interstellar gas, and the condensed phases have been predicted from chemical equilibrium thermodynamics using the solar elemental abundance (Anders \& Grevesse 1989). These dust particles contain forsterite and enstatite as the major silicates (Davis \& Richter 2003) and both water and carbon monoxide ice (Yamamoto 1983).

Dust particles from comets can reach Earth because many rocky dust particles are produced by the sublimation of ice when a comet approaches Earth. Chondritic porous interplanetary dust particles (CP-IDPs) consist of fluffy and fine-grained anhydrous Mgrich silicates (forsterite and enstatite; Klöck et al. 1989; Bradley 2003) and have been assumed to originate from comets owing to their unusually high Mn contents.

Chondrules are small silicate droplets that cooled rapidly from silicate melt in the solar nebula and consist mainly of coarse-grained crystals of olivine, pyroxene and Fe-Ni metal; they are the main constituents of unequilibrated chondrites. Chondrule diameters vary between chemical groups of chondrites, with mean values of $0.15,0.3,1.0,0.7,0.2,0.3$, 0.5 and $0.6 \mathrm{~mm}$ for CO3, CM2, CV3, CR2, EH3, H3, L3, and LL3, respectively (Scott \& Krot 2005). Fig. 1 illustrates representative examples of the different chemical groups. 


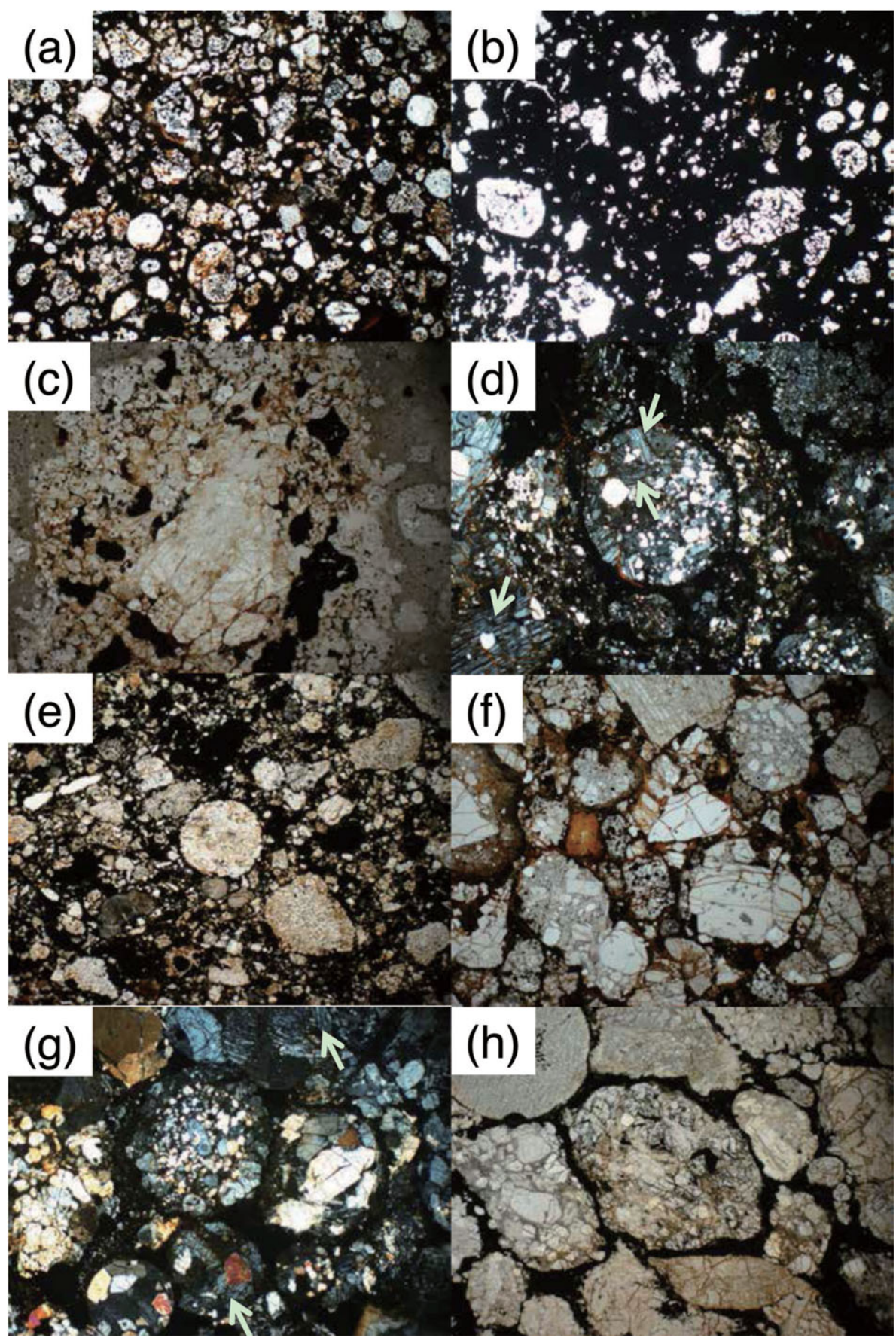

Figure 1. Photographs of unequilibrated chondrites under an optical microscope. The side of each photo is $2.3 \mathrm{~mm}$. (a)-(c): Irregularly shaped chondrules are abundant. (d)-(h): Rounded chondrules are abundant. (a) Yamato-81020 CO3 chondrite. Open nicol. (b) Yamato 980051 CM2 chondrites. Open nicol. (c) Yamato-86751 CV3 chondrite. Open nicol. (d) Yamato-793495 CR2 chondrite. Polysynthetic twinning of pyroxene is observed. Cross nicol. (e) Yamato-691 EH3 chondrite. Open nicol. (f) Yamato-82038 H3 chondrite. Open nicol. (g) Yamato-74191 L3 chondrite. Polysynthetic twinning of pyroxene is observed. Cross nicol. (h) Allan Hills-764 LL3 chondrite. Open nicol. 
Recently, cometary dust particles from comet $81 \mathrm{P} /$ Wild 2 were successfully recovered by the Stardust mission (Brownlee et al. 2006), and chondrule-like objects consisting of massive coarse grains were found to comprise many of the recovered particles (Nakamura et al. 2008). Additionally, many Antarctic micrometeorites (hereafter, AMMs) have been shown to be texturally and compositionally similar to these chondrule-like objects. Such massive coarse-grained particles have been collected only from polar regions: interplanetary dust particles collected from the stratosphere are generally $\leqslant 20 \mu \mathrm{m}$ in diameter and are predominantly fine grained.

In this study, we analyzed the texture and composition of AMM samples, and used a comparison between these samples and those from comet $81 \mathrm{P} /$ Wild 2 to verify the appropriateness of existing models of chondrule formation.

\section{Methods}

AMMs sampled in this study were recovered from the Tottuki icefield (28 AMMs bearing relicts among identified 99 AMMs; Iwata \& Imae 2002) and the water well at Amundsen-Scott Station (68 MMs bearing relicts among identified 373 AMMs, Taylor et al. 1998). The diameters of collected AMMs were primarily $50-100 \mu \mathrm{m}$, which is within the usual size range for micrometeorites reaching Earth from space, based on the size and mass distributions of extraterrestrial particles obtained from a recovered artificial satellite (Love \& Brownlee 1993). This implies that AMMs represent the major cosmic components on Earth.

Candidate AMM samples were lined individually with adhesive carbon tape. Then, the samples were observed and analyzed by secondary electron microscopy with an attached energy dispersive system (SEM-EDS). The EDS detected the coexistence of magnesium, silicon and iron, suggesting a cosmic origin; this is supported by backscattered electron images (BSEs) that display a welded surface morphology due to heating during atmospheric entry. Polished sections of the AMM samples were made to allow observation of internal texture and analysis of constituent minerals (using an electron probe microanalyzer: JEOL, JXA-8200). Based on textural observations and compositional analyses, AMMs and their relict phases were determined.

\section{Results and Discussion}

\subsection{Size and Composition of Chondrule-like Objects in Cometary Dust}

The mean size of grains constituting chondrule-like objects in AMMs was found to be slightly lower $(\sim 10-20 \mu \mathrm{m})$ than that of chondrules in meteorites $(\geqslant 30 \mu \mathrm{m}$; Nakamura et al. 2008), i.e., the chondrule-like objects in our study exhibit smaller diameters than chondrules in chondritic meteorites.

Compositional differences (particularly in terms of olivines and pyroxenes) have been recognized between chondrule-like objects from comets and chondrules in chondritic meteorites: $\mathrm{MnO}$ contents in forsterites and enstatites in the chondrule-like objects of comets are distinctly higher than those in chondritic meteorites (Fig. 2). Although the chemical formula of pure forsterite ( $\mathrm{Mg}$ end-member of olivine) is $\mathrm{Mg}_{2} \mathrm{SiO}_{4}$ and that of pure enstatite ( $\mathrm{Mg}$ end-member of pyroxene) is $\mathrm{MgSiO}_{3}$, small amounts of $\mathrm{Fe}^{2+}, \mathrm{Ca}^{2+}, \mathrm{Mn}^{2+}$, $\mathrm{Al}^{3+}$ and $\mathrm{Cr}^{3+}$ can be substituted for $\mathrm{Mg}^{2+}$ in forsterite and enstatite to form a solid solution series. The compositions of forsterites and enstatites in $81 \mathrm{P} / \mathrm{Wild} 2$ are clearly different from those in chondrites (Figs. $2 \mathrm{a}-2 \mathrm{~d}$ ): forsterites and enstatites in cometary dust are slightly enriched in $\mathrm{Mn}(\mathrm{MnO} \geqslant 0.5 \mathrm{wt} \%)$ compared to chondritic meteorites 
(a)
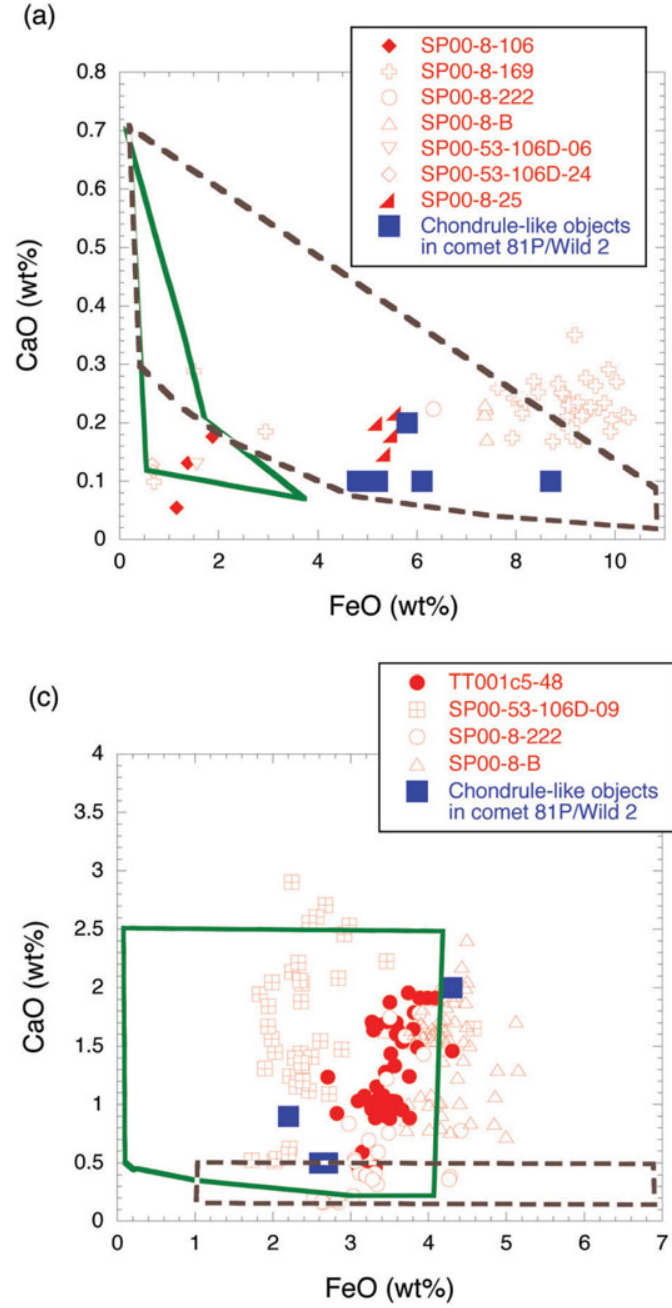

(b)

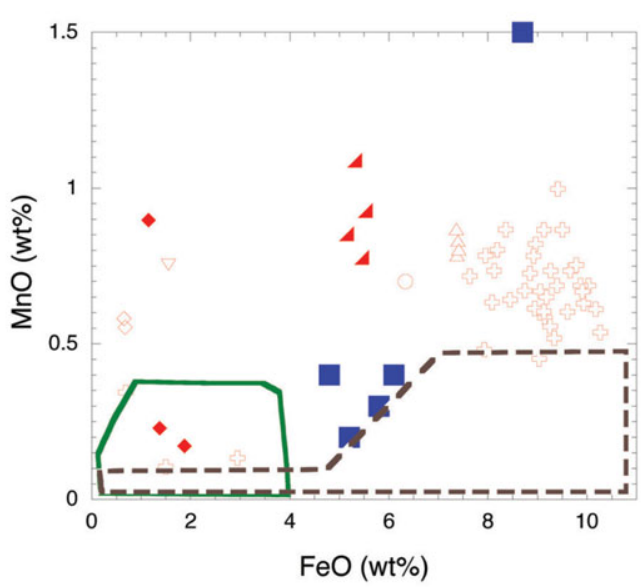

(d)

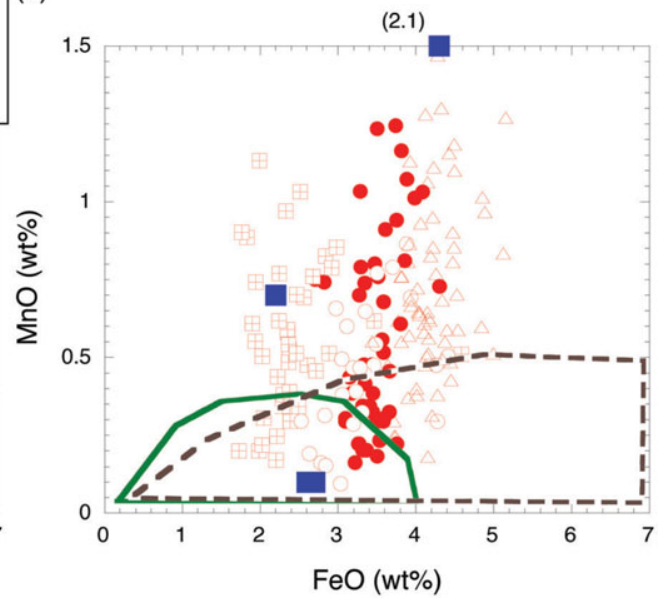

Figure 2. Compositions of Antarctic micrometeorites from comet and comet 81P/Wild 2 with the compositional range of carbonaceous chondrites (indicated as the area enclosed by the solid line) and unequilibrated ordinary chondrites (indicated as the area enclosed by a dotted line). (a) $\mathrm{FeO}-\mathrm{CaO}$ plot for forsterite. (b) FeO-MnO plot for forsterite. (c) FeO-CaO plot for enstatite.

(d) $\mathrm{FeO}-\mathrm{MnO}$ plot for enstatite.

$(\mathrm{MnO} \leqslant 0.5 \mathrm{wt} \%)$. The slightly ferroan forsterites and enstatites $(\mathrm{FeO}=2-8 \mathrm{wt} \%)$ in chondrule-like objects of comet $81 \mathrm{P} /$ Wild 2 are also distinguishable from those in carbonaceous chondrites $(\mathrm{FeO}=1-2 \mathrm{wt} \%)$.

Of the collected AMMs, we identified 13 consistent with chondrule-like objects in comet $81 \mathrm{P} /$ Wild 2; four of these are shown in Fig. 3. The chondrule-like objects are characterized by coarse-grained and poikilitic textures (Figs. 3a-3d); similar textures have been observed in the chondrule-like objects of comet 81P/Wild 2 (Nakamura et al. 2008). Furthermore, we have noted close similarities between high-Mn AMMs and chondrulelike objects in terms of ferroan olivine and ferroan low-Ca pyroxenes, and the detail will be described with the present Mg-rich phases elsewhere. 


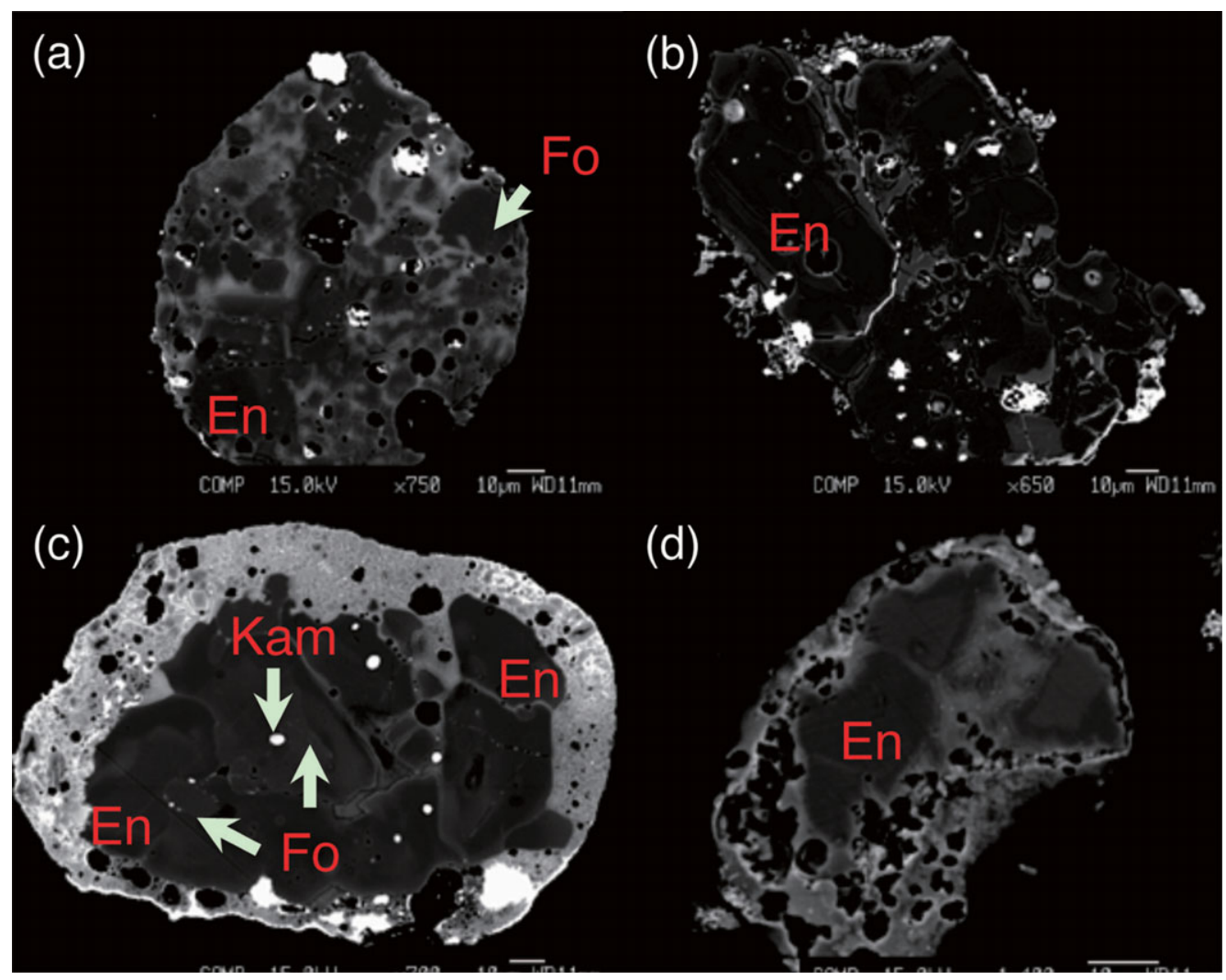

Figure 3. Back-scattered electron images of Antarctic micrometeorites from comets. (a) SP008-222. (b) SP00-53-106D-09. (c) SP00-8-B. (d) TT001c5-48. Fo = forsterite. En = enstatite. $\mathrm{Kam}=$ kamacite $(\mathrm{Fe}-\mathrm{Ni}$ alloy) .

\subsection{A New Constraint on Chondrule Formation}

$\mathrm{Mn}$, which is slightly more volatile than magnesium and iron, is enriched in cometary dust; thus, chondrule formation in the asteroid belt would have occurred under refractory conditions, while chondrule formation in the Kuiper belt would have occurred under Mnrich conditions.

The different compositions of precursors for chondrules could be ascribed to different regions of chondrule formation for comets and chondritic meteorites. If this was the case, chondrules would have formed in both the Kuiper belt region and the asteroidal region, which contradicts models in which chondrule formation accompanies the X-wind (Shu et al. 1996; Liffman 1996), although the small grain size of chondrule-like objects is as expected based on the X-wind model. Rather, the results of the present study correspond more closely to those expected based on the shock heating model (e.g., Nakamoto et al. 2005).

\subsection{On Temperatures of Chondrule Formation}

Clinoenstatite (or clinopyroxene) and high-temperature orthoenstatite (or orthopyroxene), which are polymorphs of $\mathrm{MgSiO}_{3}$, can be distinguished based on calcium contents in enstatites: the $\mathrm{CaO}$ content of clinoenstatite is less than $1 \mathrm{wt} \%$, while that of hightemperature orthoenstatite is 1-3 wt\% (Carlson 1988; Ohi et al. 2008). Clinoenstatite was inverted from protoenstatite, which is stable at high temperatures $\left(\geqslant 1000^{\circ} \mathrm{C}\right)$, and 
shows polysynthetic twinning under cross-polarized light (Figs. 1d and 1g). Clinoenstatite is common in CR2 (Fig. 1d), EH3 (Fig. 1e), H3 (Fig. 1f), L3 (Fig. 1g) and LL3 (Fig. 1h). High-temperature orthoenstatite occurs in carbonaceous chondrites and comets, but less so in unequilibrated chondrites and enstatite chondrites. Clinoenstatite formed by transition from protoenstatite at temperatures lower than $\sim 1000^{\circ} \mathrm{C}$. Protoenstatite crystallizes at higher temperatures $\left(\leqslant 1553^{\circ} \mathrm{C}\right)$ than high-temperature orthoenstatite $(\sim 1370$ $1450^{\circ} \mathrm{C}$ ) (Carlson, 1988). This suggests that the maximum temperature for chondrule formation for both carbonaceous chondrites and comets was lower than that for unequilibrated ordinary chondrites and enstatite chondrites. Chondrules are likely to have formed repeatedly in the solar nebula (e.g., Hewins 1996). The results of the present study suggest that the maximum temperature of repeated chondrule formation events in the Kuiper belt was lower than that for events in the asteroidal region.

The shape of chondrules can be interpreted in the context of pyroxene polymorphs. Clinopyroxenes showing polysynthetic twinning commonly occur in chondrules in CR2 (Fig. 1c), EH3 (Fig. 1e), H3 (Fig. 1f), L3 (Fig. 1g) and LL3 (Fig. 1h). The rounded shapes of chondrules in these chemical groups are clearer than those in CO3 (Fig. 1a), CM2 (Fig. 1b) and CV3 (Fig. 1d), in which orthoenstatite is common and clinopyroxene inverted from protopyroxene is unusual. This may be related to the temperature of chondrule formation: the degree of melting is greater for chondrules crystallizing protopyroxene than for those crystallizing orthopyroxene.

\subsection{Orthoenstatite, the Mn Carrier Phase}

Calcium is positively correlated with manganese in enstatite (Figs. 2c and 2d), and the $\mathrm{CaO}$ content of enstatite with $\mathrm{MnO} \geqslant 0.5 \mathrm{wt} \%$ is $1-3 \mathrm{wt} \%$ (Fig. 2). Clinoenstatite inverted from protoenstatite is stable in the range of up to $1 \mathrm{wt} \% \mathrm{CaO}$ content, but hightemperature orthoenstatite is stable in the range 1-3 wt\% $\mathrm{CaO}$ content (Carlson 1988; Ohi et al. 2008). Therefore, high-temperature orthoenstatite is the carrier of the Mn component. It is likely that the coexistence of high-Mn forsterite and high-Mn orthoenstatite may be due to elemental diffusion into forsterite from melt during chondrule formation and occurs owing to the speed at which the process occurs.

\section{Conclusions}

In this study, we compared textural observations and compositional analyses of chondrules in AMMs with the characteristics of chondrule-like structures in comet $81 \mathrm{P} / \mathrm{Wild}$ 2. Thirteen of the sampled AMMs displayed chondrule-like structures that were texturally similar to those in the $81 \mathrm{P} /$ Wild 2 samples, and the compositional analyses indicated striking similarities in $\mathrm{Mn}$ content for the two sources. Our results provide support for models proposing that chondrules could have formed in both the Kuiper belt and the asteroidal belt, and suggest that maximum temperatures of chondrule formation events were lower in the Kuiper belt. We believe that our results necessitate a thorough reconsideration of existing models of chondrule formation.

\section{Acknowledgments}

I am grateful to Susan Taylor for providing the SP00 micrometeorites and to Naoyoshi Iwata for collaboration in sampling at the Tottuki bare icefield. I am also grateful to Akira Miyake for discussions regarding enstatite polymorphs. The preparation of this paper was supported by an NIPR publication grant. 


\section{References}

Bradley, J. P. 2003, in: A. M. Davis (ed), Treatise on Geochemistry, vol. 1 (Elsevier), pp. 689-711

Brownlee, D., et al. 2006, Science 314, 1711

Carlson, W. D. 1988, Am. Min. 73, 232

Greenberg, J. M. \& Hage, J. 1990, Ap. J. 361, 260

Greenberg, J. M. 1998, A \& $A, 330,375$

Hewins, R. H. 1996, in: R. H. Hewins, R. H. Jones \& E. R. D. Scott (eds), Chondrules and the Protoplanetary Disk (Cambridge), pp. 3-9

Iwata, N. \& Imae, N. 2002, Ant. Met. Res. 15, 25

Klöck, W., Thomas, K. L., McKay, D. S., \& Palme, H. 1989, Nature 339, 126

Liffman, K. \& Brown, M. J. I. 1996, in: R. H. Hewins, R. H. Jones \& E. R. D. Scott (eds), Chondrules and the Protoplanetary Disk (Cambridge), pp. 285-302

Love, S. G. \& Brownlee, D. E. 1993, Science, 262, 550

Nakamura, T., Noguchi, T., Tsuchiyama, A., Ushikubo, T., Kita, N. T., Valley, J. W., Zolensky, M. E., Kakazu, Y., Sakamoto, K., Mashio, E., Uesugi, K., \& Nakano, T. 2008, Science 321, 1664

Nakamoto, T., Hayashi, M. R., Kita, N. T., \& Tachibana S. 2005, in: A. N. Krot, E. R. D. Scott \& B. Reipurth (eds), Chondrites and the Protoplanetary Disk, ASP Conference Series, vol. 341, pp. 883-892

Ohi, S., Miyake, A., Shimobayashi, N., Yashimma, M., \& Kitamura, M. 2008, Am. Min. 93, 1682

Scott, E. R. D. \& Krot, A. N. 2005, in: A. N. Krot, E. R. D. Scott \& B. Reipurth (eds), Chondrites and the Protoplanetary Disk, ASP Conference Series, vol. 341, pp. 15-53

Shu, F., Shang, H., \& Lee, T. 1996, Science 271, 1545

Taylor, S., Lever, J. H., \& Harvey, R. P. 1998, Nature 392, 899

Yamamoto, T. 1985, $A$ \& $A, 142,31$ 